\title{
COMBINED SPINAL EPIDURAL IN SINGLE INTERSPACE VERSUS EPIDURAL TECHNIQUE FOR LABOR ANALGESIA: A COMPARATIVE STUDY
}

\author{
N. V. K. Mallik ${ }^{1}$, L. Nageswara Rao 2 , Srinivasa Raju3 ${ }^{3}$ Nagaraju $M^{4}$, Nagireddy $G^{5}$ \\ ${ }^{1}$ Assistant Professor, Department of Anesthesiology, Katuri Medical College and Hospital. \\ ${ }^{2}$ Professor, Department of Anesthesiology, Katuri Medical College and Hospital. \\ ${ }^{3}$ Associate Professor, Department of Anesthesiology, Katuri Medical College and Hospital. \\ 4 Junior Resident, Department of Anesthesiology, Katuri Medical College and Hospital. \\ 5 Junior Resident, Department of Anesthesiology, Katuri Medical College and Hospital.
}

\section{ABSTRACT}

\section{AIM}

The aim of the study is to compare the onset and quality of analgesia in combined spinal epidural technique in single interspace versus sole epidural technique in attaining labour analgesia in primiparous women.

\section{METHODS}

Sixty primiparous women between age group of 20-35 years were randomly divided into two groups. Group A patients received Combined Spinal Epidural using "Needle through needle technique" and were given $2 \mathrm{ml}$ of $0.125 \%$ isobaric levobupivacaine with $25 \mathrm{mcg}$ of fentanyl for subarachnoid block and $0.125 \%$ levobupivacaine with $1 \mathrm{mcg} / \mathrm{ml}$ fentanyl at $8 \mathrm{ml} / \mathrm{hr}$ for epidural maintenance. Group B patients received sole epidural block initially with $6 \mathrm{ml}$ of $0.125 \%$ levobupivacaine with $25 \mathrm{mcg}$ of fentanyl through Tuohy needle as a bolus to achieve labor analgesia. Later, $0.125 \%$ isobaric levobupivacaine with $1 \mathrm{mcg} / \mathrm{ml}$ fentanyl at $8 \mathrm{ml} / \mathrm{hr}$ was given as continuous epidural infusion to extend analgesia.

\section{RESULTS}

A controlled study was undertaken to compare Group A with Group B for labour analgesia. The labour analgesia occurred significantly early in group A when compared to group B. The total amount of Levobupivacaine required to attain the same target level was two times in Group A ( $\mathrm{p}<0.05)$. Haemodynamic changes were comparable in both the groups. No neurological side effects were observed. In conclusion, sequential CSE is superior alternative to epidural block, which combines the advantages of spinal and epidural while minimizing their drawbacks.

\section{KEYWORDS}

Epidural, Combined Spinal Epidural, LevoBupivacaine.

HOW TO CITE THIS ARTICLE: Mallik NVK, Rao LN, Raju S. et al. "Combined spinal epidural in single interspace versus epidural technique for labor analgesia: a comparative study." Journal of Evolution of Medical and Dental Sciences 2015; Vol. 4, Issue 104, December 28; Page: 16919-16922, DOI: 10.14260/jemds/2015/2548

\section{INTRODUCTION}

Epidural and spinal blocks are major regional techniques with a long history of effective use for a variety of procedures and pain relief. Nevertheless, both techniques have their drawbacks. Precipitous hypotension and difficulty in controlling the level of analgesia are major disadvantages of spinal block. ${ }^{1}$

However, epidural block with the catheter technique gives a better control of the level of analgesia and can be used for providing postoperative pain relief by opioids or local anaesthetic agents. But, it still has its drawbacks such as slower onset of action, patchy anaesthesia, more doses of local anaesthetics and hazard of cardiovascular and neurotoxicity. ${ }^{2}$

Financial or Other, Competing Interest: None.

Submission 11-12-2015, Peer Review 12-12-2015,

Acceptance 24-12-2015, Published 26-12-2015.

Corresponding Author:

Dr. N. V. K. Mallik,

Staff Qtrs- $A-10$,

Chinakondrupadu,

Guntur.

E-mail:nvkmallik@gmail.com

DOI:10.14260/jemds/2015/2548
The CSE technique aims to provide the benefits of spinal block with the flexibility of an indwelling epidural catheter to extend the duration of analgesia into the postpartum period. It was introduced by Soresi. ${ }^{3}$ in 1937 using "Single needlesingle interspace" technique.

Later on various modifications and different methods came into use, each having some advantages over the other. The CSE block can be used for a variety of surgeries. ${ }^{4}$ and also for relief of labor pain..$^{5}$ and postpartumpain. ${ }^{6}$

The technique of sequential CSE involves injection of low dose of subarachnoid local anaesthetic and then extension of block by injecting drug through the epidural catheter. The purpose of this study was to evaluate sequential CSE and epidural block in terms of labor analgesia, motor sparing and hemodynamic response.

\section{MATERIALS AND METHODS}

It was a prospective, randomized, double blind study. Sixty patients of ASA physical status I and II aged 20-35 primiparous women were included. The approval of institutional research committee and informed consent were obtained. Patients having neurological or coagulation disorder, pregnancy induced hypertension, hypotension, emotional instability, unwillingness and any anticipated 
difficulty in regional anaesthesia were excluded from the study.

All patients were premedicated with Inj. Ranitidine $50 \mathrm{mg}$, Inj. Ondansetron 8mg intravenously before Procedure. Preloading was done with Ringer Lactate $10 \mathrm{ml} / \mathrm{kg}$ were randomly divided into two groups of 30 each. Group A: CSE block using "Needle through needle single interspace" technique. Group B: Sole Epidural block with catheter insertion. The blocks were given in sitting position in both the groups under strict aseptic precautions.

In Group A, 16-G Tuohy needle was introduced into epidural space using loss of resistance technique with air filled syringe. A long 27-G Whitacre spinal needle was inserted through the Tuohy needle with back eye opening and advanced until the tip was felt to penetrate the duramatter. $2 \mathrm{ml}$ of $0.125 \%$ isobaric levobupivacaine with 25 mcg of Inj. fentanyl was injected through spinal needle with the aim of achieving immediate pain relief. The spinal needle was then withdrawn. A 16-G epidural catheter was inserted, secured and its patency was checked. The dose of $8 \mathrm{ml}$ of $0.125 \%$ isobaric levobupivacaine with $1 \mathrm{mcg} / \mathrm{ml}$ fentanyl into epidural space via catheter as continuous infusion was started.

In Group B, 16-G Tuohy needle was introduced using the same technique to identify the epidural space and after giving $3 \mathrm{ml}$ of $1 \%$ lignocaine with 1:200,000 adrenaline as test dose, $6 \mathrm{ml}$ of $0.125 \%$ isobaric levobupivacaine with $25 \mathrm{mcg}$ of Inj. Fentanyl was injected to achieve labor analgesia. Then, the epidural catheter was introduced and the block was prolonged by using $8 \mathrm{ml}$ continuous infusion of $0.125 \%$ isobaric levobupivacaine along with $1 \mathrm{mcg} / \mathrm{ml}$ Inj. Fentanyl.

Loss of sensation was tested by pinprick method by an operator, who was blinded to the type of block given at $5 \mathrm{~min}$ intervals till maximum level of block was achieved and thereafter every 15 minutes. The quality of labor analgesia was assessed by anaesthesiologist and was graded as:

- Excellent : No supplementary drug required

- Good : Analgesic required.

- Fair : More than one analgesic required.

Duration of analgesia was taken from onset of sensory block to two-segment regression time. The degree of motor sparing of lower limb was assessed according to modified Bromage scale.

- 0 : No paralysis

- 1: Inability to raise the extended knee

- 2: Inability to flex the knee

- 3: Inability to flex the ankle joint

All clinical data are presented as Mean \pm Standard deviations. Statistical analysis was carried out using the unpaired two tailed Students t-test and c2 test wherever appropriate. A p value of $<0.05$ was considered statistically significant.

\section{RESULTS}

Both groups were comparable in terms of age, weight, height and ASA grading (Table-1). The mean onset time of analgesia in group A was significantly shorter as compared to group B (Table 2). The level of analgesia obtained by single dose of local anaesthetic was comparable in both the groups, i.e. the quality of analgesia was excellent in $85 \%$ of patients in group A as compared to $40 \%$ in group B $(\mathrm{p}<0.05)$.

However, none of the patients in both groups had poor quality of analgesia (Table-3).

\begin{tabular}{|c|c|c|c|}
\hline Variable & Group A & Group B & P \\
\hline No. of Patients & 30 & 30 & \\
\hline Age (yrs) & $26.5 \pm 4.51$ & $25.5 \pm 5.18$ & $>0.05$ \\
\hline Weight $(\mathrm{kg})$ & $54.85 \pm 6.71$ & $56.05 \pm 6.21$ & $>0.05$ \\
\hline Height $(\mathrm{cm})$ & $158.55 \pm 5.64$ & $159.2 \pm 5.16$ & $>0.05$ \\
\hline Primiparous & $30 / 30$ & $30 / 30$ & \\
\hline \multicolumn{4}{|c}{ Table 1: Demographic Data } \\
\hline
\end{tabular}

Hemodynamic parameters such as pulse rate and blood pressure were monitored at five minute intervals for one hour and thereafter every fifteen minutes. The total dose of levobupivacaine and requirements of analgesic, sedative, antiemetic and any complications were recorded and fetal heart rate monitoring was done continuously.

\begin{tabular}{|c|c|c|c|}
\hline Parameter & Group A & Group B & P \\
\hline $\begin{array}{c}\text { Onset of analgesia } \\
\text { (min) }\end{array}$ & $10 \pm 5$ & $25 \pm 7.07$ & $<0.05$ \\
\hline $\begin{array}{c}\text { Total amount of levo- } \\
\text { bupivacaine (mg) }\end{array}$ & $42.6 \pm 12.6$ & $113.5 \pm 11.78$ & $<0.05$ \\
\hline \multicolumn{4}{|c|}{ Table 2: Onset and Amount of Anaesthetic used } \\
\hline
\end{tabular}

Data presented as Mean \pm Standard deviation.

Significant difference between the two groups.

\begin{tabular}{|c|c|c|}
\hline Parameter & Group A & Group B \\
\hline Quality & & $8(40 \%)$ \\
\hline Excellent & $17(85 \%)$ & $9(45 \%)$ \\
\hline Good & $2(10 \%)$ & $3(15 \%)$ \\
\hline Fair & $1(5 \%)$ & 0 \\
\hline Poor & 0 & Table 3: Quality of Labor Analgesia \\
\hline \multicolumn{2}{|r|}{}
\end{tabular}

Data presented as number of patients (Percentage)

There was significant difference between the groups.

Transient motor blockade for a period of $10 \mathrm{~min}$ was observed in group A as compared to group B. Extent of motor blockade using modified Bromage scale was assessed. The total amount of levobupivacaine required to reach the same level, i.e. was approximately two times in group B as Hemodynamic changes during labor analgesia were comparable in both the groups (Table 4). Maximum number of patients in both groups had fall of $10-20 \%$ in blood pressure and heart rate.

\begin{tabular}{|c|c|c|}
\hline & Group A & Group B \\
\hline \% Fall in PR & & \\
\hline$<10 \%$ & 4 & 3 \\
\hline $10-20 \%$ & 14 & 17 \\
\hline $20-30 \%$ & 10 & 8 \\
\hline$>30 \%$ & 2 & 2 \\
\hline \% Fall in Systolic BP & & \\
\hline$<10 \%$ & 4 & 12 \\
\hline $10-20 \%$ & 15 & 11 \\
\hline $20-30 \%$ & 8 & 5 \\
\hline$>30 \%$ & 3 & 2 \\
\hline \multicolumn{2}{|c|}{ Table 4: Haemodynamic Parameters } \\
\hline \multicolumn{2}{|c}{}
\end{tabular}


Data presented as number of patients. $\mathrm{PR}=$ pulse rate; $\mathrm{BP}=$ blood pressure. No significant difference between the two groups.

Adverse effects observed in the study are tabulated in Table 5. Counselling was required in significantly higher number of patients in group B as compared to group A. None of the cases complained of post-dural puncture headache.

Fetal heart rate monitoring was done continuously during the procedure till the delivery of the baby. No signs of fetal hypoxia and distress were observed in both the groups.

\begin{tabular}{|c|c|c|c|}
\hline & Group A & Group B & $\mathbf{P}$ \\
\hline Nausea \& Vomiting & 1 & 0 & $>0.05$ \\
\hline Pruritus & 6 & 4 & $>0.05$ \\
\hline Backache & 7 & 9 & $>0.05$ \\
\hline PDPH & 0 & 0 & $>0.05$ \\
\hline \multicolumn{4}{|c|}{ Table 5: Adverse Effects } \\
\hline
\end{tabular}

Data presented as number of patients, $\mathrm{PDPH}=$ Post Dural Puncture Headache.

\section{DISCUSSION}

In the present study, the labor analgesia, the onset and quality in Group A were superior to those seen in Group B. The onset time for sensory analgesia in Group A was significantly shorter than in group B. Various studies comparing combined spinal epidural with sole epidural anesthesia observed similar results in terms of analgesia and motor sparing. ${ }^{4}$

The early onset and quality of sensory blockade of Group A may be due to spinal component in CSE anesthesia. The need for supplementary analgesics and counseling were significantly higher in group B when compared with group A. The higher incidence of supplementation and failure rate in patients receiving epidural block has been reported by many workers. 7,8

The dose of levobupivacaine required to produce sensory block necessary for labor analgesia was two times more with group B as compared to group A. Rawal et al. ${ }^{7}$ also observed similar findings with CSE group. In our study, two patients of the group A had accidental dural puncture with Tuohy's needle and were excluded from the study.

Hemodynamically, the incidence of hypotension and bradycardia was almost similar in both the groups. The majority of the patients in both groups had a mild fall of 10 $20 \%$ in pulse rate and blood pressure. Only 2 patients of group A and 2 patients of group B had fall of $>30 \%$ in pulse rate, which responded to atropine. Hypotension of $>30 \%$ was seen in 3 patients of group A and 2 patients in group B, which was due to aortocaval compression, was subsided after left lateral tilt. In group A, although spinal block is given initially, significant haemodynamic changes are not observed because of lesser sympathetic blockade due to sequential CSE technique combined with slower onset of epidural block. This allows more time for compensatory mechanism to be effective. 7,9

None of the patients complained of post dural puncture headache. The use of 27-G Whitacre spinal needle may have contributed to the absence of PDPH in our study. Norris et al. ${ }^{10}$ also found less incidence of PDPH in patients receiving CSE as compared to epidural block. Similar observation was noted in other studies also.4,6,7,9 Post spinal headache occurring with CSE block can be managed by IV infusion of fluids. ${ }^{11,12}$ or drug. ${ }^{7}$

We have used the single interspinous space block technique in Group A, which appears to be safer, time saving and less traumatic. ${ }^{13,14}$ as compared to double interspace technique. The mechanism of action of epidural continuous infusion in CSE block is not clear. Various hypothesis laid down. 5 are:

- Continued spread of drug originally injected into the subarachnoid space.

- Leakage of epidural drug via the hole in dura into subarachnoid space.

- Cephalad displacement of CSF and subarachnoid drug due to dural compression by epidural fluid (volume effect), epidural pressure changes (becoming atmospheric) altering the spread of spinal drug.

- Epidural blockade unmasking the effect of subclinical spinal blockade above the clinical level of blockade.

- Compression of subarachnoid space by the presence of epidural catheter and by the volume of local anaesthetic, resulting in a "squeezing" of CSF and more extensive spread of local anaesthetic.

The risk of catheter migration through dural hole made by spinal needle can also be argued, but use of CSE needle with 'back eye,' as used in our study ensures that the epidural catheter reaches the dura at a point away from the dural puncture. Furthermore, it is impossible to force 16-G epidural catheter through the hole made by $27-\mathrm{G}$ spinal needle.5 Thus the technique using needle with 'back eye' appears safe.

In conclusion, combined spinal epidural analgesia is found to be a better and superior alternative to sole epidural analgesia for labor analgesia. Advantages offered by CSE are faster onset of action, superior quality of analgesia and less dose of local anaesthetic required to attain desired quality of labor analgesia (Sequential CSE). The incidence and severity of hypotension and bradycardia is similar with both the groups. Thus CSE offers the best of both spinal and epidural technique and has a promising future in regional anaesthesia and postoperative analgesia. ${ }^{15}$

\section{REFERENCES}

1. Datta S, Alper MH, Ostheimer GW, et al. Method of ephedrine administration and nausea and hypotension during spinal anesthesia for cesarean section. Anesthesiology 1982; 56:68-70.

2. Thorburn J, Moir DD. Bupivacaine toxicity in association with extradural analgesia for caesarean section. Br J Anaesth 1984; 56:551-553.

3. Soresi A. Episubdural anesthesia. Anesth Analg 1937; 16:306-10.

4. Holmstrom B, Laugaland K, Rawal N, et al. Combined spinal block versus spinal and epidural block for orthopedic surgery. Can J Anaesth 1993; 40:601-6.

5. Rawal N, Zundert AV, Holmstrom B, et al. Combined spinal epidural technique. Reg Anesth 1997; 22(5):406-423.

6. Collis RE, Davis DW, Aveling W. Randomized comparison of combined spinal epidural and standard epidural analgesia in labor. Lancet 1995; 345:141316. 
7. Rawal N, Schollin J, Wesstrom G. Epidural versus spinal epidural block for Caesarean section. Acta Anaesthesiol Scand 1988; 32:61-6.

8. Scott DB, McClure JH, Giasi RM, et al. Effects of concentration of local anesthetic drugs in extradural block. Br J Anaesth 1980; 52:1033-1037.

9. Thoren T, Holmstrom B, Rawal N, et al. Sequential combined spinal epidural block versus spinal block for cesarean section: Effects on maternal hypotension and neuro behavioural function of the newborn. Anesth Analg 1994; 78:1087-1092.

10. Norris MC, Grieco WM, Borkowsi M, et al. Complications of labor analgesia: epidural versus combined spinal epidural techniques. Anesth Analg 1994; 79:529-37.

11. Mumtaz MH, Daz M, Kuz M. Another single space technique for orthopedic surgery. Anaesthesia 1982;37:90.
12. Coates MB. Combined subarachnoid and epidural techniques. A single space technique for surgery of the hip and lower limb. Anaesthesia 1982; 37:69-70.

13. Casati A, DcAmbrosio A, DeNegri P, et al. A clinical comparison between needle-through-needle and double-segment techniques for combined spinal and epidural anesthesia. Reg Anesth Pain Med 1998; 23:390-394.

14. Joshi G, McCaroll S. Evaluation of combined spinalepidural anesthesia using two different techniques. Reg Anesth 1994; 19:169-174.

15. Dr Priya Gupta, et al. Sequential combined spinalepidural versus epidural anaesthesia in orthopaedic and gynaecological surgery: A comparative evaluation. Indian J Anaesthesia 2002; 46(6):453-456. 